\title{
Os almanaques e a literatura em Angola no séc. XIX
}

\author{
Almanacs and poetry in Angola in \\ the 19th century XIX
}

Francisco Soares

FURG

\section{DoI}

https://doi.org/10.37508/rcl.2021.n46a462

\section{RESUMO}

Breve consideração sobre almanaques e enciclopedismo. Relatório sucinto acerca da pesquisa efetuada sobre os almanaques que se publicaram em Angola no século XIX, ou onde publicaram poetas a partir de Angola. O texto vai acompanhado por três anexos: tabela de autores e publicações enviadas para o Almanach de Lembranças a partir do que hoje é Angola; Lista de autores e lugares de onde enviaram poemas; lista de autores citados nas colaborações líricas.

Palavras-Chave: Angola; Almanaques; século XIX.

\section{Abstract}

Brief consideration on almanacs and encyclopedism. A brief report about the research done on the almanacs that were published in Angola in the 19th century, or where poets from Angola published. The text is accompanied by three annexes: table of authors and publications sent to 
the Almanach de Lembranças; list of authors and places from which they sent poems; list of authors cited in lyric collaborations.

KEYWORDS: Angola; Almanacs; 19th century.

\section{Introdução}

Qualquer resquício fica sempre entre nós do que foi o enciclopedismo (compreenderão porque está sem maiúscula), não tanto na origem, mas em parte da sua receção. De resto, apesar de o Enciclopedismo ficar marcado por uma postura muito clara de superação do ambiente cultural anterior, ele começa por se inspirar num dicionário de artes e ciências (e notícias, opiniões e informações as mais diversas, em inglês), a Cyclopcedia de Ephraim Chambers (CHAMBERS, 1728). É certo que Diderot critica Chambers na entrada Encyclopédie:

Les articles de Chambers sont assez régulierement distribués,mais ils sont vuides ; les nôtres sont pleins mais irréguliers. Si Chambers eût rempli les siens, je ne doute point que son ordonnance n'en eût souffert. (COSTE, 2009, p. 12).

Mas a sua Enciclopédia, como é sabido (CYCLOPÆDIA, s. d., s.p.; DIDEROT’S Encyclopédie, s.d., s.p.), começou por ser a tradução-versão da de Chambers, encomendada em 1749 por um livreiro francês. A leitura comparada das entradas (por exemplo Antopologia, Homem, entradas relativas à Mecânica e à Física sob responsabilidade de d'Alembert e por via de vários palimpsestos (COSTE, 2009) mostra isso. Esse dicionário estava bem mais próximo do tipo de leitor que hoje procura enciclopédias do que a Encyclopédie francesa. Desenvolvendo um pouco os termos de entrada, a Cyclopæedia de Chambers funcionava como um "ensina-burros”, um dicionário um pouco mais desenvolvido que nos esclarecia o suficiente sobre palavras-chaves.

O resquício fútil de enciclopedismo que refiro, ligado à distração, frivolidade, ocasionalidade ou casualidade, juntas à busca de con- 
selhos e informações úteis ou gerais, fazia uma espécie de enciclopedismo de bolso, cuja origem remota poderá estar na leitura do Lunário e pronóstico perpétuo - se não formos até aos calendários manuscritos lembrados por Luís de Albuquerque e aos almanaques “perpétuos” (ANASTÁCIO, 2014, p. 8). Aliás, a tradução e versão para português, assumida por António da Silva de Brito desde 1703 (MEDEIROS, 2015, p. 166-167), bem como as constantes atualizações, esclarecem-nos sobre as apetências do público (CORTÊS, 1805) do Lunário perpétuo e, posteriormente, dos almanaques. Parece contraditório juntar informações úteis e gerais, frivolidade e casualidades com o projeto francês da Enciclopédia? Possivelmente. O enciclopedismo não pretendia ser fútil, opunha-se de resto a lunários e astrologias, mas a pretensão de reunir tudo num só volume, ou projeto, era já de si fútil e serviu bem mais o propósito de propagar a nova postura rapidamente para todos os campos intelectuais ou científicos, em concorrência com os obscurantismos (e também com Chambers). Essa pretensão, traduzida para uma larga faixa de público menos interessado no aprofundamento filosófico de cada item, realizava-se nos almanaques. A estrutura de ambos os tipos de publicação (enciclopédia, almanaque) era, claro, bem diferente. As entradas das enciclopédias ainda hoje são feitas por ordem alfabética, as entradas dos almanaques ordenavam-se pelo calendário. Não é disso que eu falo, nem o meu texto se motiva na comparação estrutural de ambos os tipos. Falo dessa pretensão de reunir e divulgar o maior número possível de 'conhecimentos úteis', fossem técnicos ou científicos, ou mesmo costumeiros (no caso dos almanaques). Essa pretensão podia satisfazer-se em diversas estruturas editoriais,

$1 \mathrm{O}$ uso de aspas simples destina-se, neste ensaio, a referir expressões comuns na oralidade, na qual adquirem, por vezes, cambiantes ou nuances específicas que podem ser transpostas para a escrita e com as quais eu não me comprometo ao recorrer a essas palavras. 
mas todas elas tinham a sustentá-las uma apetência comum de um público vasto e com interesses diferentes também. No horizonte de expetativas da época, a popularidade dos almanaques vinha de serem, simultaneamente, um recheio de calendário, no qual as doses de conhecimento eram dadas por pequenos textos simples escalonados no decurso dos dias do ano.

Olhando mais à frente um pouco (relativamente à emergência das enciclopédias), para muitas leitoras e muitos leitores dos dois últimos séculos era bom ter ali 'tudo à mão', com o desenvolvimento mínimo necessário. É por esse filão que segue a irônica mas empenhada explanação de Eça de Queiroz acerca dos almanaques, oportunamente citada por Vanda Anastácio. Eça preparou o texto "para servir de prefácio ao Almanaque Encyclopédico de 1896" (ANASTÁCIO, 2014, p. 5-6), uma espécie de almanaque realista e cientificista. O título é, de si, significativo para o que venho levantando. Repare-se entretanto neste excerto:

Então, naquele caminho perdido da Mesopotâmia, sob a imensa tristeza do céu justiceiro, os dois Sábios, filhos de Seth, determinaram arquivar, escrevendo sobre matéria imperecível, a Ciência que possuíam, que era a Ciência total daquela primeira Humanidade. Durante três dias e três noites (...) os Sábios, sem repouso, ansiosamente, espreitando as nuvens, gravavam sobre o granito e sobre o tijolo, duplamente, o Livro de Todo-o Saber. (...) Que direi? O Livro de Todo-o Saber, gravado para a Humanidade vindoura, sobre o tijolo e o granito, nas vésperas do Dilúvio, por dois sábios filhos de Seth, era na realidade e simplesmente um Almanaque. (QUEIROZ, 1895, p. 32, 34).

A particular adaptação do almanaque ao público em geral, também segundo Eça, viria de ser ele uma espécie de calendário ilustrado, preenchido, orientador: 
Só o Almanaque verdadeiramente nos penetra na realidade da nossa Existência, porque a circunscreve, a limita, a divide em talhões regulares, curtos, compreensíveis, fáceis de desejar e depois fáceis de recordar porque têm nome, e quase têm forma, e onde se vão depondo e vão ficando os factos da nossa feliz ou desgraçada História. As datas, e só elas, dão verdadeira consistência à vida e à sua evolução. (QUEIROZ, 1895, p. 60).

A natural inclinação totalizante, em simultâneo com a nossa tendência para não perder muito tempo 'com essas coisas', faz-nos abraçar leituras que nos alimentem, ou corrijam qualquer simulacro de tudo, velozmente e sem esforço, atualizando uma imagem provisória do conjunto a partir de pequenos fragmentos de 'realidade' e previsão - diários no caso dos almanaques. Essa imagem global é preenchida com mais rigor pela Enciclopédia, que refere tudo o que nós queremos e devemos saber e o faz desenvolvendo as entradas. A sua mistura com folhinhas mais antigas e práticas abre-nos as portas dos almanaques do século XIX (CHAVES, 2014, p. 44-45).

Quando falo dessa apetência antiga do público, não refiro nada que tenha perecido sob os trepidantes avanços tecnocientíficos do século XX. Hoje essa procura reconfigurou-se e mantém-se viva no mercado editorial. Procurando, nas livrarias ou em rede, por títulos como Guia dos curiosos, obtemos várias ofertas interessantes e, quiçá, surpreendentes. Mas há práticas não-editoriais possibilitadas pela internet e que também são sintomáticas. Ainda que não nos dê lucro, muitos de nós pesquisamos em rede, certas horas do dia ou semana, por lazer. Há vezes em que lemos títulos interessantes em publicações periódicas, revistas, jornais, blogues, etc., deparamos com títulos e abrimos a hiperligação para ver o que é; ou saltitamos de umas para outras páginas sem nenhum propósito fixo. As informações disponíveis em rede prestam-se a isso. A internet oscila entre a Grande Enciclopédia e o contínuo almanaque - para além de uma vasta coleção de asneiras, algumas pouco divertidas. Ali se 
encontra 'tudo', muito mais que no 'ensina-burros'. Depois, mesmo que isso não tenha qualquer interesse para a nossa profissão, nem para a sobrevivência da espécie, lemos um texto, breve, exploramos hiperligações e guardamos algumas das páginas que vimos ou, por vezes, redistribuímos entre os nossos contactos.

Retornando ao antigamente, na vida (VIEIRA, 2005) fazia-se o mesmo percorrendo enciclopédias, operando-se a redistribuição pelos contactos em reuniões sociais, cartas, ou conversas a propósito. A alternativa à enciclopédia, sobretudo no século XIX, residia nas publicações periódicas e, em particular, nos almanaques². Os periódicos tinham sempre uma secção chamada "Curiosidades”, ou com título indicando uma idêntica funcionalidade. Isso atraía vários tipos de leitores 'enciclopédicos' e até mesmo eruditos ou sábios. Os almanaques operavam por atualizações anuais e setoriais de 'conhecimentos úteis', datas, frivolidades, bizarrias, curiosidades, distrações (POMBO, 2021, p. 180). Com sugestões de seriedade e sobriedade, por vezes os editores destacavam alguns artigos, "pois é sem dúvida o melhor meio de espalhar os conhecimentos de geral utilidade o publicá-los de modo a serem relidos." (LAEMMERT; LAEMMERT, 1847, p. VII).

No meio de mistura tal apareciam poemas, igualmente para distrair, ou por serem curiosos, ou episódicos. Outros, enfim, por serem de poetas famosos, dos quais importava citar algum verso de vez em quando para a gente se mostrar à la page. Alguns dos poemas para distração, nos contextos de rara oportunidade de publicação como o angolano, podem ser importantes para estudarmos a comunidade

2 Segundo Inocêncio Francisco da Silva, o "primeiro ensaio ou tentativa que n'este género apareceu em Portugal" saiu em 1757, das oficinas de Francisco Luís Ameno e por ele organizado. O segundo sairia por alvará de D.a Maria I de 22.3.1871, sob responsabilidade ou patrocínio da Academia Real das Ciências de Lisboa. (SILVA, 1868, p. 44). Inocêncio pensava, com certeza, nas publicações mais parecidas com as do seu século. 
e a semiosfera na qual se iniciou uma dada literatura. Nesse caso, pesquisar almanaques é necessário para teóricos da literatura (e da cultura) e para pesquisadores em História da Literatura, bem como para pesquisadores das mais variadas áreas.

Anuários desses espalhavam-se pelas cidades-porto do mundo e daí para o interior, sobretudo na segunda metade do século XIX. O comércio levava a uma globalização de conhecimentos curiosos e frívolos (a maioria frívolos ao nível da receção), a par das utilidades. Eles propagavam um ambiente mental, funcionavam numa semiosfera que se globalizava e nos permitia exibi-los em qualquer sociedade 'culta', 'civilizada', 'urbana', etc. - mesmo quando se referiam a particularidades exóticas e 'primitivas'. Além de informações práticas para diversas atividades, aplicavam-se nas reuniões fúteis, efêmeras, com pessoas 'polidas', 'educadas', 'instruídas' e 'informadas'. O paradigma tinha raiz europeia, de onde se espalhava por todo o mundo, conforme também os interesses e negociantes europeus se deslocalizavam para as mais diversas paragens. O caso, já posterior, da popularidade mundial das Seleções do Reader's Digest (revista fundada em 1922 nos EUA) demonstra a vitalidade pública do interesse por tal tipo de periódico ao longo do século XX.

Para os habitantes letrados de portos com pequeno volume de negócios e de pequenas urbanidades, era muito mais vantajoso ler almanaques estrangeiros e participar deles do que fazer um local, destinado aos vizinhos - empreendimento economicamente pouco recomendável. Acho que se deve, em boa parte, a isso o facto de rarearem almanaques produzidos localmente nos portos de Benguela e de Luanda no século XIX. Após a abolição do tráfico, o porto de Luanda seria mais movimentado que o de Benguela, mas nada se o comparamos com os grandes cais de outros continentes ou do Mediterrâneo, que suscitavam uma organização cada vez mais complexa; quanto ao porto de Benguela, iria decair até ser substituído pelo do Lobito já no século seguinte. Suspeito que não fomos a única 'pro- 
víncia ultramarina' portuguesa com tal escassez de produção local (ANASTÁCIO, 2014, p. 18-19).

\section{Almanaques em Angola}

No nosso caso, publicou-se em Luanda um Almanak statístico da província d’Angola e suas dependências (ALMANAK statístico da Província d'Angola e suas dependências, 1852, s.p.). Era sintomático da viragem que referi, no sentido de se fazerem publicações anuais úteis, informativas, acordadas a um espírito rigoroso, técnico e científico. Reunia, em 55 páginas, informação diversificada sobre o nosso espaço colonial e suas fronteiras internas. O título ganhou corpo nos “prelos da Imprensa do Governo" e seria destinado ao ano seguinte, o que pode gerar confusão (LOPO, 1964, p. 12, 17, 20, 41). Embora dedicado ao ano de 1852 e com data de 1851 (a referida por Inocêncio Francisco da Silva, que teve um exemplar (SILVA, 1858, p. 43)), foi publicado já no próprio ano de 1852 (dois anos depois do primeiro Almanach de lembranças, o modelo de sucesso na lusografia do tempo). Com uma passagem do periódico (afinal, de número único), Castro Lopo justifica a emenda feita a Inocêncio, pois ali se escreve que "em princípio de Fevereiro" de 1852, "por motivos estranhos à redação", o volume ainda não entrara em fase de composição (LOPO, 1964, p. 41). É possível que tais dificuldades fossem recorrentes e de cariz técnico. Seriam do mesmo tipo que explicava o desfasamento nas datações encontrado nas Espontaneidades da minha alma, de Maia Ferreira (o único livro de poemas então impresso em Angola) - nesse caso entre as datas de 1849 e 1850 (FERREIRA, 2018). Havia só uma tipografia, a oficial, e ela tinha de priorizar o papel e as tintas para publicações oficiais. As novas remessas não chegariam regularmente, nem em quantidade bastante para assegurar outras impressões em tempo calendarizado. É certo que diferentes motivos ainda podiam limitar ou atrasar a saída do Almanak, porém não conheço nenhum. 
O título recorda vários outros, como o Almanak estatistico de Lisboa (PORTUZAL, 1843, s.p.). Para dar outro exemplo o Almanak administrativo, mercantil e industrial do Rio de Janeiro, saído sob responsabilidade dos conhecidos editores Laemmert e que se começara a publicar em 1843 (LAEMMERT; LAEMMERT, 1843), ganhando maioridade a partir de 1850 . Ambos se reportam a um escopo geográfico e temático específico e o nosso mais ainda que o brasileiro ou o português. Júlio de Castro Lopo transcreve também o propósito, característico e localizado para a província de Angola:

...notícia resumida dos estabelecimentos públicos e seus empregados, divisão administrativa, população, clima, produções, indústria rural e fabril, comércio, legislação, governo, força militar, religião, instrução pública, rendimento e despesa, catálogo dos governadores e uma breve notícia do país e seus habitantes em geral, por nos parecer que uma tal publicação será bem acolhida do público, pela sua reconhecida utilidade. (LOPO, 1964, p. 41).

Mais útil do que a maioria dos almanaques, na medida em que reunia informação objetiva e qualificada para aquele lugar, mas também muito mais específico, o periódico não teve grande saída (podia, certamente, haver outros motivos para a sua descontinuação). Mas, até hoje, a sua leitura é fundamental para se elaborar um estudo da situação da província nesse ano e nos que o antecederam (FERREIRA R., 2014)3). Era, portanto, um volume de informação, mais que de diversão.

Só vinte anos mais tarde saiu segundo almanaque em Luanda. Formatado em " $8 .^{\circ}$ francês" (em vez do in $4 .^{\circ}$ do Statístico), tinha também menos páginas (39 apenas). Imprimiu-se na tipografia de $O$ mercantil, o jornal do séc. XIX que maior duração conseguiu na ca-

$3 \mathrm{O}$ artigo não fala propriamente sobre o Almanak statístico. É pela análise das referências às suas páginas que se torna evidente a minha afirmação. 
pital da colônia, saindo sob responsabilidade de J. P. da Silva Rocha, português residente. Posto à venda na primeira quinzena de fevereiro de 1872 , há nele a registar a crônica, de saboroso elogio a Luanda, feita por José Cardoso Vieira de Castro (LOPO, 1964, p. 46-48), sob o pseudônimo "Samuel". J. C. Vieira de Castro foi o mais famoso degredado português desses anos (viria, aliás, a falecer meses mais tarde). Chamava-se ela "Improvizo n'um toast" (ou seja: num brinde).

No Arquivo Histórico Nacional de Luanda, vi referência a um "Almanaque de Mossamedes" para 1883, que teria sido publicado pelo Jornal de Mossâmedes. Infelizmente, o exemplar não foi disponibilizado para consultas. Carolina Corso de Carvalho, sob orientação de A. Hohlfeldt, refere o mesmo título, porém com a data de 1884 (CARVALHO; HOHLFELDT, s.d., s.p.). Aida Freudenthal baliza a existência do jornal entre 1881 e 1895 (FREUDENTHAL, 2001).

Não tenho conhecimento de qualquer outro almanaque publicado entre nós ao longo do século XIX. No entanto, a presença do tipo não nos era alheia, só que preferíamos os de circulação transnacional - embora lusógrafa. Constata-se isso mesmo por duas vias: 1) espreitando alguns títulos encontrados em fontes de Luanda e de Benguela; 2) consultando as colaborações enviadas de Angola para o famoso Almanach de lembranças (CHAVES, 2014, p. 45-50).

1) No primeiro caso, para além do Almanach de lembranças, entre outras fontes encontrei duas referências interessantes:

a. Eduardo Neves, um português aclimatado residente no Dondo, colaborador assíduo no Almanach de lembranças, ainda frequentava o Almanach das senhoras - o que significa ter o título circulado pela colônia. Recorde-se que o Almanach das senhoras para Portugal e Brasil fora fundado em 1870 por D. ${ }^{a}$ Guiomar Torrezão, professora e poetisa muito respeitada nos salões elegantes do século XIX português (CARDOSO, [1917?), 
p. 162). Ele foi um filho dileto do Almanach de lembranças e teve ampla circulação pelo espaço lusógrafo, chegando a vender-se até em Espanha (MARQUES, 2019, p. 48). Constituiu um marco na afirmação feminina dentro da cultura impressa desse tempo, embora os seus conteúdos pouco diferissem do genérico do pai, sobressaindo apenas as matérias mais ligadas à feminilidade na época.

b. À saída para o séc. XX, um espólio de Benguela de 1899 menciona um "Almanaque sobre fotografias", cujo conteúdo ignoro, mas que pertencia ao naturalista português José de Anchieta, falecido em Caconda e possuidor de um ou dois laboratórios fotográficos.

2) No segundo caso, temos uma extensa lista de decifradores e compositores de charadas, poetas ou versejadores, cronistas, ou simplesmente colaboradores enviando, a partir de Angola, notícias práticas, concretas, informativas. Havia dois tipos de participantes: os filhos da terra e os reinóis, residentes estes ou de passagem.

Trabalhando com literatura, em particular com a poesia lírica, interessei-me bastante mais pelo grupo dos poetas ou versejadores. Há vários cujos dados biográficos não conheço, deles até alguns cujos verdadeiros nomes não consegui identificar. Outros deu para conhecer.

Nove dos colaboradores são seguramente oriundos de Portugal. Entre eles há quatro, de certeza, residentes (não considerei residentes os que estavam na colônia só durante uma comissão de serviço, desempenhando cargos oficiais em tempo determinado, como foi o caso de J. Cândido Furtado de Mendonça d'Antas). Há dois residentes colaboradores que não sei se eram portugueses (Alfredo de Sousa Neto e Álvaro Paes, mas há indícios de que o segundo seja do norte de Portugal e de que o primeiro teria, pelo menos, ascendência por- 
tuguesa). Angolanos houve de certeza um poeta, J. D. Cordeiro da Mata. Vários outros nomes podem ser angolanos de nascimento e criação, mas não estou seguro disso (nomeadamente A. J. Machado, Francisco José Camanha, Héli Attam).

Os dados confirmam largamente os que tenho sobre a comunidade literária local. Angolenses de nascimento ou criação, escrevendo e publicando arte literária, especialmente os que o faziam com ambição de escritores, eram muito poucos. Portugueses residentes havia mais, mas também muito poucos e com fraca ambição literária. Entre os angolenses destacava-se a figura de Cordeiro da Mata, sem dúvida. Entre os portugueses residentes, José Bernardo Ferrão (de quem se planeava publicar um livro) e Eduardo Neves. O jornalismo, na segunda metade do século, recebeu muito mais colaborações de angolenses e residentes, mas acima de tudo angolenses, do que a literatura. No entanto, apesar de não surgirem no Almanach angolenses importantes como Pedro Félix Machado, ou metropolitanos artistas da palavra como Alfredo Troni e Urbano de Castro, a mostra parece reveladora.

Já quanto aos estilos e às escolas de referência nos deparamos com diferença maior entre as colaborações líricas angolenses e a nossa produção poética. Pelo próprio figurino do Almanach de lembranças, os colaboradores angolenses e residentes situam-se no ultrarromantismo, sobretudo na sua terceira fase, a de maior vulgarização e moderadamente sensível aos sinais do futuro presente (ou seja: aquele futuro que já se manifesta mas ainda não se firmou). Chamo primeira fase do ultrarromantismo português a de João de Lemos e de O trovador em Coimbra - nessa integrando-se Gonçalves Dias na sua vivência portuguesa. A segunda fase é a de Soares de Passos e de O novo trovador - e nela se integraria (caso fosse português) José da Silva Maia Ferreira. A terceira fase é a da transição, experimentando-se formas e mudanças técnicas que aproximam a prática lírica 
das regularidades que viriam a caraterizar - formalmente - poetas realistas como Guerra Junqueiro (que foi ultrarromântico ainda no começo da sua carreira) e parnasianos como Olavo Bilac ou Pedro Félix Machado (MACHADO, 200o). Nessa transição podemos integrar as colaborações de Cordeiro da Mata e Eduardo Neves, ambos assíduos e dedicados frequentadores do Almanach e o primeiro tendo publicado um dos nossos três livros de poemas do século XIX: $D e$ lírios - versos (MATA, 2001) ${ }^{4}$. Em Cordeiro da Mata os sinais de mudança, ou de inquietação estética, surgem pelas tímidas tentativas de inovação dentro do cânone anterior. Elas observam-se nos ritmos internos dos versos e nas combinações estróficas e rímicas - usando mesmo processos similares aos de Cruz e Sousa no Brasil. Em Eduardo Neves essa mudança retoma o soneto, mas só para representar um ambiente e contar nele um curto episódio característico, típico, local - em nada semelhante ao "pic-nic" de burguesas de Cesário Verde (VERDE, 1887, p. 69); no resto a sua poesia fica próxima da de Faustino Xavier de Novaes (salvaguardadas as devidas diferenças).

As escolas, correntes e autoridades literárias também se denunciam pelos nomes de outros escritores mencionados ou aludidos nos poemas. Os aludidos escapam-nos muitas vezes e, na maioria dos casos, é difícil determinar uma fonte, porque são várias as fontes possíveis e o texto não nos esclarece o suficiente. Listei, por consequência, só os nomeados. A nomeação vem dos versos, das epígrafes e das dedicatórias. Isso traz implicações diversas e nem sempre o facto de serem nomeados significa terem sido lidos e terem impressionado o fraco poder criativo dos versejadores. Às vezes a dedicatória se deve apenas ao facto de se estar a colocar o poema no álbum de um amigo

4 Publicou-se ainda um quarto livro, de A. de Carpo, Dedo de pygmeu, mas era mais uma autobiografia em verso escrita com o intuito de 'limpar o nome' e não propriamente com a pretensão de ser um livro de poesia, nem chegando mesmo a sê-lo, na minha opinião. 
específico, ou vai acompanhada por algum pedido de favores com a voz em off. As epígrafes, em geral, atestam a leitura, pelo menos, do que se pôs ali, mas nem sempre mais do que isso. Quanto à menção dentro dos versos, ela se articula a um hipotexto (GENETTE, 1989, p. 14), explícito ou não (por indicações típicas, como "Imitação de uns versos de...”), cuja leitura se torna obrigatória. Se quisermos dimensionar as relações intertextuais envolvidas precisamos, no mínimo, de fazer uma comparação detalhada dos dois textos, o que não teria cabimento neste ensaio. Mas elas podem ir da leitura fútil e rápida à profunda reestruturação do hipertexto, como sucede em algumas composições de Maia Ferreira, incluindo uma que alguém enviou de Angola para o Almanach de lembranças (onde o autor não colaborou), já depois da sua morte.

Finalmente é importante verificarmos os lugares de onde são remetidas as composições líricas, porque eles nos darão o mapa momentâneo da criatividade literária em Angola. Esse mapa não difere muito do que supúnhamos até hoje. A esmagadora maioria dos poemas foram remetidos a partir de Luanda. Acompanhando Luanda, todo o seu hinterland, estendido até Malange, tem topónimos registados no Almanach. Benguela apresenta uma participação mais fraca do que fazia supor a existência de boas bibliotecas ali na década de 1850 , a passagem de Maia Ferreira por lá, bem como a presença de vários funcionários públicos qualificados oriundos das famílias antigas de Luanda. Mossâmedes (hoje Namibe e, entretanto, grafada Moçâmedes ainda no período colonial) enviava mais do que seria de esperar de uma colônia recente, formada sobretudo por emigrantes portugueses pobres oriundos do Brasil. A norte, o Zaire, ou Congo, rio e região (reino antigo do Kongo), a par do Ambriz, surgem também, embora não tenhamos notícia de comunidade literária ali nesse tempo de transição e desestruturação cultural e política.

Em circunstâncias como esta, devemos acrescentar que as localizações têm o seu quê de relativo. Por exemplo, Cordeiro da Mata, 
Eduardo Neves e José Bernardo Ferrão enviam muitos poemas de Luanda (Bernardo Ferrão só remete um do Dondo); no entanto eram considerados 'poetas do Quanza' e não de Luanda e sabemos que viveram a sua vida comercial afastados de Luanda, embora em contacto constante com a capital. Os próprios serviços de correios, em parte, explicariam tais distorções, mas eu refiro no quadro anexo a localização indicada quando enviam a colaboração. Isso nos indica outro desvio ainda: é que, por vezes (como sucedeu com Cândido Furtado), o poeta se localiza em Luanda não sendo provável que lá estivesse no momento em que envia o poema. Por força do motivo e da receção local isso acontecia, penso.

Não vos deixo, portanto, dados absolutos, mas indicadores de tendência nos três anexos que se seguem:

\section{1 - Tabela de autores e número de líricas enviadas de Angola}

\begin{tabular}{|l|l|l|l|}
\hline Nome & Origem & $\begin{array}{l}\text { Número } \\
\text { poemas }\end{array}$ & Datas publ.5 \\
\hline Ernesto Marecos & Port. & 1 & 1856 \\
\hline João Augusto de Sousa & Port.-r ${ }^{6}$ & 1 & 1856 \\
\hline Anonymo Benguelense & Port. & 1 & 1857 \\
\hline J. C. Furtado de M. de A. & Port. & 10 & $1859-1872 ; 1883$ \\
\hline Anónimo & Port? & 1 & 1863 \\
\hline
\end{tabular}

continua

5 As datas dizem respeito ao ano para que se destina o Almanach. Geralmente as colaborações eram enviadas entre 1 a 2 anos antes.

6 Português residente.

7 Possivelmente o mesmo João Augusto de Sousa. 


\begin{tabular}{|c|c|c|c|}
\hline Nome & Origem & $\begin{array}{l}\text { Número } \\
\text { poemas }\end{array}$ & Datas publ.5 \\
\hline Valentim A. M. da Silva & Port. & 1 & 1866 \\
\hline José Bernardo Ferrão & Port.-r & 6 & $1868-1889$ \\
\hline M. da C. & Port? & 1 & 1873 \\
\hline C. M. & $?$ & 2 & $1874 ; 1876$ \\
\hline Narciso J. N. Braga & Port? & 1 & 1877 \\
\hline Alfredo de Souza Neto & Port?-r & 2 & $1878-1882$ \\
\hline Rogado & Port? & 3 & $1879-1881$ \\
\hline J. D. Cordeiro da Mata & Ang. & 17 & $1879-1897$ \\
\hline Eduardo P. F. Neves & Port.-r & 12 & $1880-1892$ \\
\hline Alberto Carvalho & Port? & 1 & 1880 \\
\hline Álvaro Paes & Port?-r & 2 & 1882 \\
\hline Um vimaranense & Port. & 2 & $1882 ; 1885$ \\
\hline Francisco M. Q. de Assis & Port? & 2 & $1882-1884$ \\
\hline Augusto Maria Lilla & Port? & 3 & $1883^{-1886}$ \\
\hline A. C. (de) Moraes & Ang? & 2 & $1886 ; 1887$ \\
\hline Judith & Port? & 1 & 1886 \\
\hline Joaquim de Jesus Ferreira & Port? & 5 & $1887-1899$ \\
\hline Abílio A. G. Mendanha R. & Port.-r & 4 & $1887 ; 1895$ \\
\hline Augusto G. de Castro & Port? & 2 & 1887 \\
\hline Pedro Joaquim de Mesquita & Port? & 1 & 1887 \\
\hline
\end{tabular}




\begin{tabular}{|c|c|c|c|}
\hline Nome & Origem & $\begin{array}{l}\text { Número } \\
\text { poemas }\end{array}$ & Datas publ.5 \\
\hline A. J. Machado & $?$ & 2 & $1887 ; 1890$ \\
\hline J. F. d'Abreu & Port? & 1 & 1887 \\
\hline Um desmemoriado & $?$ & 1 & 1888 \\
\hline João de Lemos & $?$ & 2 & $1889 ; 1893$ \\
\hline Júlia de Mesquita & $?$ & 1 & 1889 \\
\hline Alberto Marques Pereira & Port. & 10 & $1889-1895$ \\
\hline João Lino Mariz & Ang? & 1 & 1890 \\
\hline Francisco J. Camanha & Ang? & 1 & 1890 \\
\hline Héli Attam & Ang? & 1 & 1893 \\
\hline Francisco M. Gouvea & $?$ & 1 & 1893 \\
\hline Jorge de Lucena & $?$ & 4 & $1894^{-1900}$ \\
\hline Marcos Algarve & Port? & 1 & 1900 \\
\hline
\end{tabular}

Lugares de onde se remeteram colaborações líricas

\begin{tabular}{|l|l|l|}
\hline Autor & Onde se localiza $^{8}$ & Pa o ano de \\
\hline Ernesto Marecos & Sem indicação de lugar & 1856 \\
\hline João Augusto de Sousa & Benguela9 & 1856 \\
\hline Anonymo Benguelense & Benguela & 1857 \\
\hline
\end{tabular}

8 Não se referem poemas enviados de fora de Angola.

9 O nome dos lugares está com grafia atual. 


\begin{tabular}{|c|c|c|}
\hline Autor & Onde se localiza ${ }^{8}$ & Pa o ano de \\
\hline $\begin{array}{l}\text { J. Cândido Furtado de M. de } \\
\text { Antas }\end{array}$ & $\begin{array}{l}\text { Luanda } \\
\text { “ } \\
\text { Angola } \\
\text { Luanda } \\
\text { “ }\end{array}$ & $\begin{array}{l}1863 ; 1864 ; \\
1865 ; \\
1867 \\
\text { “ } \\
1868 ; 1883\end{array}$ \\
\hline Anónimo & Sem indicação de lugar & 1863 \\
\hline Valentim A. Monteiro da Silva & Mossâmedes & 1866 \\
\hline José Bernardo Ferrão & $\begin{array}{l}\text { Luanda } \\
\text { “ } \\
\text { “ } \\
\text { Dondo - Margens do Quanza }\end{array}$ & $\begin{array}{l}1868 ; 1878 \\
1879 ; 1880 \\
1881 \\
1889\end{array}$ \\
\hline M. da C. & Luanda & 1873 \\
\hline C. M. & $\begin{array}{l}\text { Rio Zaire } \\
\text { ، }\end{array}$ & $\begin{array}{l}1874 \\
1876\end{array}$ \\
\hline Narciso José Nogueira Braga & Zaire & 1877 \\
\hline Alfredo de Souza Neto & Luanda & $1878 ; 1882$ \\
\hline Rogado & $\begin{array}{l}\text { África } \\
\text { “ }\end{array}$ & $\begin{array}{l}1879 ; 1880 \\
1881\end{array}$ \\
\hline J. D. Cordeiro da Mata & $\begin{array}{l}\text { Luanda } \\
\text { Barra do Quanza } \\
\text { “ } \\
\text { Angola } \\
\text { Luanda } \\
\text { “ } \\
\text { Barra do Quanza } \\
\text { Tombo - Margens do Quanza } \\
\text { Barra do Quanza } \\
\text { Sem indicação de lugar }\end{array}$ & $\begin{array}{l}1879 ; 1881 \\
1884 ; 1886 \\
1886 ; 1886 \\
1887 \\
1888 ; 1889 \\
1890 ; 1890 \\
1890 ; 1890 \\
1891 ; 1892 \\
1892 \\
1897\end{array}$ \\
\hline
\end{tabular}




\begin{tabular}{|c|c|c|}
\hline Autor & Onde se localiza $^{8}$ & Pa o ano de \\
\hline Eduardo Neves & $\begin{array}{l}\text { Dondo (Margens do Quanza) } \\
\text { Luanda } \\
\text { “ } \\
\text { Dondo } \\
\text { Dondo - África } \\
\text { Sem indicação de lugar } \\
\text { Luanda }\end{array}$ & $\begin{array}{l}1880 \\
1881 ; 1882 \\
1884 ; 1885 \\
1890 ; 1890 \\
1891 \\
1892 \\
1892\end{array}$ \\
\hline Alberto Carvalho & Luanda & 1880 \\
\hline Álvaro Paes & Luanda & $1881 ; 1882$ \\
\hline Um Vimaranense & $\begin{array}{l}\text { Ambriz } \\
\text { Zaire }\end{array}$ & $\begin{array}{l}1882 \\
1885\end{array}$ \\
\hline $\begin{array}{l}\text { Francisco Maria Quintella de } \\
\text { Assis }\end{array}$ & Luanda & $1882 ; 1884$ \\
\hline Augusto Maria Lilla & $\begin{array}{l}\text { Casengo - África Ocidental } \\
\text { Quilengues }\end{array}$ & $\begin{array}{l}1883 ; 1884 \\
1886\end{array}$ \\
\hline A. C. de Moraes & Luanda & $1886 ; 1887$ \\
\hline Judith & D... & 1886 \\
\hline $\begin{array}{l}\text { Joaquim de Jesus Ferreira } \\
\text { I. I. F. } \\
\text { J. J. F. }\end{array}$ & $\begin{array}{l}\text { Pungo Andongo - África } \\
\text { África Ocidental - P. A. } \\
\text { Quissol - Angola }\end{array}$ & $\begin{array}{l}1887 ; 1888 \\
1890 \\
1894 ; 1899\end{array}$ \\
\hline A. A. G. Mendanha Raposo & $\begin{array}{l}\text { Malange - África Ocidental } \\
\text { Luanda - África Ocidental }\end{array}$ & $\begin{array}{l}1887 \\
1892 ; 1893\end{array}$ \\
\hline Augusto Guilherme de Castro & Quilengues - África & $1887 ; 1887$ \\
\hline Pedro Joaquim de Mesquita & Mossâmedes & $1887 ; 1890$ \\
\hline A. J. Machado & Malange - África Ocidental & 1887 \\
\hline J. F. d'Abreu & Zaire & 1887 \\
\hline
\end{tabular}




\begin{tabular}{|c|c|c|}
\hline Autor & Onde se localiza $^{8}$ & Pa o ano de \\
\hline Um Desmemoriado & Luanda & 1888 \\
\hline João de Lemos & $\begin{array}{l}\text { Luanda } \\
\text { Rio Zaire }\end{array}$ & $\begin{array}{l}1889 \\
1893\end{array}$ \\
\hline Júlia de Mesquita & Mossâmedes & 1889 \\
\hline Alberto Marques Pereira ${ }^{10}$ & $\begin{array}{l}\text { Luanda } \\
\text { “ } \\
\text { “ } \\
\text { “ } \\
\text { “ } \\
\text { Sem indicação de lugar }{ }^{11}\end{array}$ & $\begin{array}{l}1889 ; 1890 \\
1890 ; 1890 \\
1890 ; 1891 \\
1892 ; 1893 \\
1893 \\
1895\end{array}$ \\
\hline João Lino Mariz & $\begin{array}{l}\text { Maianga da Viúva Clara - } \\
\text { Luanda }\end{array}$ & 1890 \\
\hline Francisco José Camanha & Mossâmedes & 1890 \\
\hline Héli Attam & Luanda & 1893 \\
\hline Francisco M. Gouvêa & Luanda & 1893 \\
\hline Jorge de Lucena & $\begin{array}{l}\text { Luanda } \\
\text { Sem indicação de lugar }{ }^{12} \\
\text { Angola }\end{array}$ & $\begin{array}{l}1894 ; 1894 \\
1897 \\
1900\end{array}$ \\
\hline Marcos Algarve & Congo Português & 1900 \\
\hline
\end{tabular}

10 A primeira vez que aparece o nome aparece "Ferreira", mas acho que foi por gralha.

11 Poema localizado e datado: "Loanda, janeiro, 20 - 88."

12 A cena, ou episódio, é localizada - por nota - em Ambaca. 


\section{2 - Lista de autores citados nas colaborações enviadas de Angola}

1. Alice Moderno - no soneto "Vingança", assinado por Paulo (1892/205, "Loanda"), que lhe é dedicado.

2. Alexandre Herculano - na composição de "Um Vimaranense" (1882/48, composição dedicada a A. H.).

3. Alfredo "Trony" - numa composição de Eduardo Neves $(\mathrm{S} 1890 / 167)$.

4. Anónimo ("adágio"; ditado latino) - numa composição de Eduardo Neves (1885/157); numa composição de A. J. Machado (S1887/162).

5. António Xavier Rodrigues Cordeiro - numa composição de Eduardo Neves (1882/54), enquanto diretor do Almanach, e em outra de F. M. Quintella d'Assis (1882/173, na dedicatória).

6. Augusto Maria Lilla - numa dedicatória em poema de "Judith..." (1886/314).

7. Boileau - numa composição de "Um desmemoriado" (1888/218).

8. Da Amália Vieira do Nascimento - numa composição de Augusto Maria Lilla (1886/50).

9. Eduardo Neves - numa composição de Jorge de Lucena (1897/99) e em outra de José Bernardo Ferrão (1889/133, dedicatória).

10. Faustino Xavier de Novaes - numa composição de Eduardo Neves (1881/100) e em outra de Héli Attam (1893/206).

11. Francisco Maria Quintella de Assis - numa composição de Eduardo Neves (1885/157, composição dedicada a ele).

12. J. B. L. de Almeida Garrett - numa composição de Marcos Algarve $(1900 / 342)$. 
13. J. B. Rousseau ${ }^{13}$ - numa composição de Alfredo de Souza Neto (1882/121, composição dedicada a J. B. Rousseau).

14. Jeremias (o profeta da Bíblia) - numa composição de J. C. Furtado d'Antas (1865/165).

15. João de Lemos - num poema de Cândido Furtado (1881/66)

16. João Eusébio da Cruz Toulson - numa composição de J. D. Cordeiro da Mata (1888/333).

17. Júlio Diniz - numa composição de Alberto Marques Pereira (1890/383).

18. Lefranc de Pompignam - numa composição de Alfredo de Souza Neto $(1882 / 121)$.

19. Luís de Camões - numa composição de Marcos Algarve $(1900 / 342)$

20. Miguel de Cervantes - numa composição de J. C. Furtado d'Antas $(1865 / 165)$.

21. Molière (J. B. Poquelin) - numa composição de J. D. Cordeiro da Mata (S1889/128).

22. Pedro Félix Machado - numa composição de Eduardo Neves $(1891 / 316)$.

23. Pierre Siéfert - numa composição de Alberto Marques Pereira (S1890/61).

24. Raynouard - numa composição de Alfredo de Souza Neto $(1878 / 375)$.

25. Thomaz Ribeiro - D. Jayme, numa composição de José Bernardo Ferrão (1878/202).

13 Trata-se do dramaturgo parisiense (1671-1741), não confundir com o pensador Jean-Jacques Rousseau. 
26. Victor Hugo - numa composição de F. M. Quintella d'Assis (1884/66), e em quatro de Cândido Furtado (1859/338; 1867/374; $1868 / 264 ; 1875 / 124)$.

27. W. Shakespeare - numa composição de Alberto Marques Pereira (1890/383) e em outra de Francisco José Camanha (S189o/147), que repete o mesmo verso de Alberto Marques Pereira.

RECEBIDO: 17/07/2021 APROVADO: 15/08/2021

\section{REFERÊNCIAS}

ALMANAK statístico da Província d'Angola e suas dependências. Luanda (Angola): (s.n.), 1852.

ANASTÁCIO, V.. Almanaques: Origem, géneros, produção feminina. In: L. Areias; L. d. Pinheiro. (Editores). As mulheres e a imprensa periódica. Lisboa (Portugal): CLEPUL, 2014. p. 5-32

CARDOSO, N. C. Poetisas portuguesas. Lisboa (Portugal): Livraria Científica, (1917?).

CARVAlHo, C. C.; HOHLfeldT, A. C.. A Imprensa Colonial de Expressão Portuguesa: a imprensa de Angola. In: Eu sou Famecos. Porto Alegre, s.d.. Disponível em: http://eusoufamecos.uni5.net/nupecc/wpcontent/uploads/2011/05/jornalismo-colonial-portugues.pdf. Acesso em: 8 jun. 2021.

CHAMBERS, E.. Cyclopodia; or, An Universal Dictionary of Arts and Sciences ( $1^{\mathrm{a}} \mathrm{ed}$.). Londres (Inglaterra): (s.n.), 1728.

CHAVES, V. P.. Notícia do Almanaque de Lembranças e das suas "Senhoras". In: L. Areias; L. d. Pinheiro. (Editores). As mulheres e a imprensa periódica. Lisboa (Portugal): CLEPUL, 2014. p. 43-66.

CÓRTES, J.. O non plus ultra do lunario, e pronostico perpetuo, geral e particular para todos os Reinos e Provincias. Lisboa (Portugal): Ofic. de Joaquim Thomaz de Aquino Bulhões, 1805.

COSTE, A. Air, the making of. Recherches sur Diderot et sur l'Encyclopédie, 44: Sur un Air d'Encyclopédie, pp. 9-14. Langres (França): Société Diderot, (outubro de) 2009. 
CYCLOPADIA. In: ENCYCLOPEDIA Britannica. Chicago (Estados Unidos da América), Britannica, T. Editors of Encyclopaedia. Disponível em: https://www.britannica.com/topic/Cyclopaedia. Acesso em: 22 mar. 2018.

FERREIRA, J. da S. M. Espontaneidades da minha alma: às senhoras africanas. $2^{\mathrm{a}}$ ed. Lisboa (Portugal): Edições 70, 1980.

FERREIRA, J. da S. M. Espontaneidades da minha alma: às senhoras africanas. $3^{\text {a }}$ ed. Luanda: UEA, 1985.

FERREIRA, J. da S. M. Espontaneidades da minha alma: às senhoras africanas. Lisboa: Imprensa Nacional-Casa da Moeda, 2002.

FERREIRA, J. da S. M. Espontaneidades da minha alma: às senhoras africanas. Porto (Portugal): Sombra pela Cintura, 2018.

FERREIRA, R.. Abolicionismo versus colonialismo: Rupturas e continuidades em Angola (século XIX). In: Mulemba. 2014. v. 4. n. 8. p. 101-126.

FREUDENTHAL, A. Voz de Angola em tempo de ultimato. In: Estudos Afro-Asiáticos. Rio de Janeiro, ano 23, n. 1, p. 135-169, 2001. Disponível em: https://www.scielo.br/j/eaa/a/qwj7rSxFvSbnLSPdPDGTgrw/?lang=pt. Acesso em: 22 jun. 2021.

GENETTE, G.. Palimpsestos: La literatura en segundo grado.Tradução de C. F. Prieto. Madrid: Taurus, 1989.

LAEMMERT, E.; LAEMMERT, H.. Almanak administrativo, mercantil $e$ industrial do Rio de Janeiro. Rio de Janeiro: Laemmert, 1843.

LAEMMERT,E.;LAEMMERT,H.. Advertência.In:Almanakadministrativo, mercantil e industrial do Rio de Janeiro. Rio de Janeiro: Laemmert, 1847. p. VII-VIII.

LOPO, J. d.. Jornalismo de Angola: subsídios para a sua história. Luanda (Angola): Centro de Informação e Turismo, 1964.

MACHADO, P. F.. Sorrisos e desalentos. Lisboa: Imprensa Nacional-Casa da Moeda, 2000.

MARQUES, A. L de V.. "O Almanach tudo desvenda... tudo ensina": sociabilidades, mediação cultural e elementos cívico-educacionais nos impressos Brasil-Portugal (1899-1903). 2019. Tese (Doutorado em Educação). Universidade Federal da Paraíba. Disponível em: https:// repositorio.ufpb.br/jspui/bitstream/123456789/15857/1/Arquivototal. pdf. Acesso em: 12 jun. 2021. 
MATA, J. D.. Delírios: versos. Lisboa: Imprensa Nacional-Casa da Moeda, 2001.

MEDEIROS, A. da S.. Notas sobre a produção, a circulação e a leitura do Lunário Perpétuo de Jerônimo Cortez entre Portugal e o Brasil. In: Revista Portuguesa de História, n. 46. 2015. p. 163-184.

POMBO, O.. Curiosidade e Ciência. In: Electra, n. ${ }^{\circ}$ 12, (primavera de) 2021. p. $167-180$.

PORTUZAL, M. A. (Org.). Almanak Estatistico de Lisboa em 1843. Lisboa (Portugal): Typ. do Grátis, 1843.

QUEIROZ, E. de. Almanaques. In: Almanaque enciclopédico para 1896. Lisboa (Portugal): Livraria de Antonio Maria Pereira, 1895.

SILVA, I. F. Dicionário bibliográfico português. Tomo primeiro. Lisboa (Portugal): Imprensa Nacional, 1858.

SILVA, I. F. Dicionário bibliográfico português: estudos Tomo oitavo. Lisboa (Portugal): Imprensa Nacional, 1867.

SILVA, I. F. Dicionário bibliográfico português Tomo nono. Lisboa (Portugal): Imprensa Nacional, 1870.

VERDE, C. O livro de Cesário Verde: 1873-1886. (Publicação organizada por Silva Pinto). Lisboa: Typographia Elzeviriana, 1887.

VIEIRA, J. L. No antigamente, na vida. Lisboa (Portugal): Caminho, 2005.

DIDEROT'S Encyclopédie. In: Virginia Museum of History \& Culture [sítio eletrônico). Disponível em: https://virginiahistory.org/learn/diderotsencyclopedie. Acesso em: 06 jun. 2021.

\section{MiNicuRRículo}

Francisco Soares - Prof. Visitante no PPG-Letras da FURG; membro do CITCEM da FLUP. Prof. Associado, com Agregação, pela Universidade de Évora. Prof. Titular na Univ. Agostinho Neto. Lattes: http://lattes.cnpq. br/1985490987306681. Orcid: https://orcid.org/oooo-0oo2-6074-4904. 